Supplement of The Cryosphere, 12, 1347-1365, 2018

https://doi.org/10.5194/tc-12-1347-2018-supplement

(C) Author(s) 2018. This work is distributed under

the Creative Commons Attribution 3.0 License.

(c) (1)

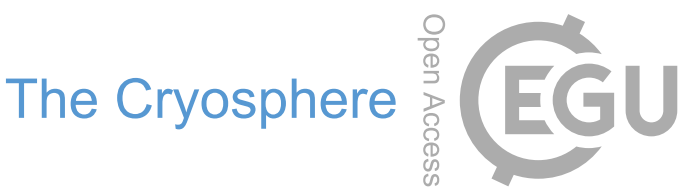

Supplement of

\title{
Recent dynamic changes on Fleming Glacier after the disintegration of Wordie Ice Shelf, Antarctic Peninsula
}

Peter Friedl et al.

Correspondence to: Peter Friedl (peter.friedl@dlr.de)

The copyright of individual parts of the supplement might differ from the CC BY 3.0 License. 


\section{S1 Data used for front line delineation}

Table S1: Data used for mapping the front positions in Fig. 1, 2, 3, 6 and S6.

\begin{tabular}{|c|c|c|c|}
\hline Year & Platform & Reference & Date \\
\hline 1966 & Aerial photography & Ferrigno, 2008 & $11 / 121966$ \\
\hline 1974 & Landsat-1 & Ferrigno, 2008 & 1974-01-06 \\
\hline 1989 & Landsat-3 & Ferrigno, 2008 & $1989-02-20$ \\
\hline 1994 & ERS-1/2 & & 1994-02-01 \\
\hline 1995 & ERS-1/2 & & $1995-10-27$ \\
\hline 1996 & ERS-1/2 & & $1996-02-10$ \\
\hline 1997 & ERS-1/2 & & $1997-01-29$ \\
\hline 1998 & ERS-1/2 & & $1998-01-30$ \\
\hline 1999 & ERS-1/2 & & $1999-11-10$ \\
\hline 2000 & ERS-1/2 & & $2000-02-20$ \\
\hline 2001 & Landsat-7 & & 2001-01-04 \\
\hline 2002 & ERS-1/2 & & $2002-02-23$ \\
\hline 2003 & ERS-1/2 & & 2003-01-24 \\
\hline 2004 & ERS-1/2 & & 2004-03-03 \\
\hline 2005 & ERS-1/2 & & $2005-01-28$ \\
\hline 2007 & ERS-1/2 & & 2007-02-02 \\
\hline $2008^{*}$ & Envisat & Wendt et al., 2010 & 2008-04-13 \\
\hline $2008^{*}$ & Envisat & & 2008-11-08 \\
\hline 2009 & ASTER & Wendt et al., 2010 & 2009-02-02 \\
\hline 2010 & ERS-1/2 & & $2010-02-26$ \\
\hline 2011 & TSX/TDX & & 2011-11-23 \\
\hline 2012 & TSX/TDX & & $2012-10-16$ \\
\hline 2013 & TSX/TDX & & $2013-12-08$ \\
\hline 2014 & TSX/TDX & & 2014-11-03 \\
\hline 2015 & Sentinel 1a & & 2015-09-09 \\
\hline 2016 & Sentinel 1a & & 2016-01-31 \\
\hline
\end{tabular}

*The 2008-04-13 front position is shown in Fig. 1 and the 2008-11-08 front position is shown in Fig. 6 and S6. 


\section{S2 Error estimation of surface velocity measurements}

The corresponding errors of the velocity measurements were estimated as described in detail in Seehaus et al. (2015). It is assumed that the resulting uncertainties for each velocity field are induced by two major sources: the coregistration process and the tracking algorithm itself. The error caused by residual inaccuracies of the coregistration $\left(\sigma_{V}^{C}\right)$ was determined by

5 calculating the median velocity for 19 to 64 points on stable non-moving surfaces (e.g. rock outcrops) (Fig. S1). The error induced by the tracking algorithm $\left(\sigma_{V}^{T}\right)$ was estimated according to the following formula, modified from McNabb et al. (2012):

$$
\sigma_{V}^{T}=\frac{c \Delta x}{z \Delta t}
$$

where $C$ is the uncertainty of the tracking algorithm (assumed to be 0.4 pixels), $\Delta x$ is the image resolution (mean values for

10 each sensor are listed in Tab. S2), $z$ is the oversampling factor (we applied a factor of two) and $\Delta t$ is the temporal baseline between the SAR images. The total error $\left(\sigma_{V}\right)$ of the velocity measurement is the sum of $\sigma_{V}^{C}$ and $\sigma_{V}^{T}$. Table S3 lists the values $\Delta t, \sigma_{V}^{C}, \sigma_{V}^{T}$ and $\sigma_{V}$ for each velocity field. As in Seehaus et al. (2015) the quite large $\sigma_{V}^{T}$ values for ERS-1/2 measurements during one of the sensor's "Tandem" or "Ice Phases", where the satellites orbited in 1- or 3-day repeat passes, were excluded from our estimation of $\sigma_{V}$. 


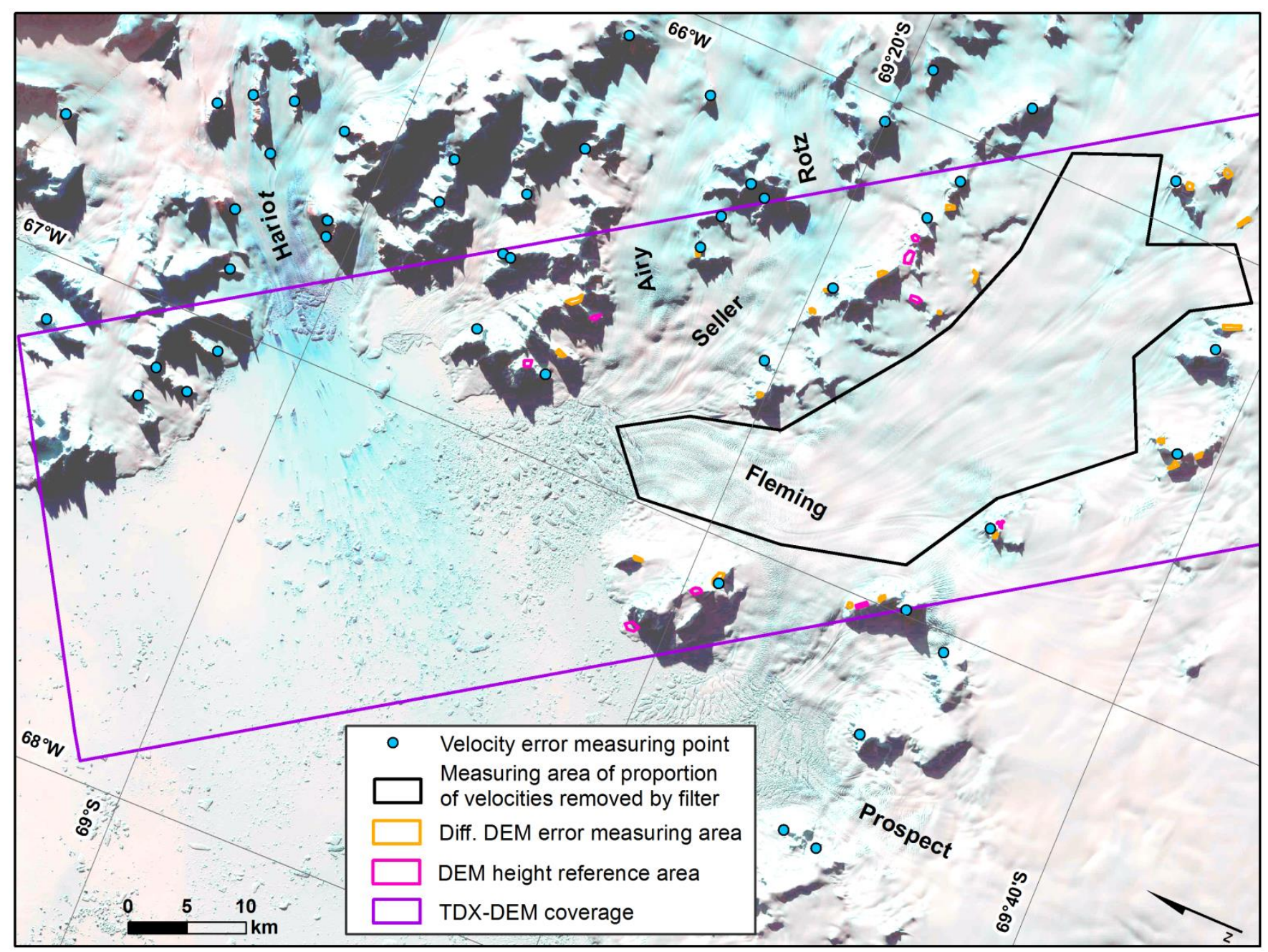

Figure S1: Blue dots: Stable points used for the coregistration error estimation of the intensity tracking results; Black polygon: reference area for the calculation of the proportion of velocity measurements removed by the filter of Burgess et al. (2012) (values of each velocity field are listed in Tab. S.3). Orange polygons: stable areas on nunataks and hills for accuracy assessment of elevation change 5 measurements. Pink polygons: stable areas on nunataks and hills for vertical height referencing of the TanDEM-X DEMs. Purple polygon: spatial coverage of the TanDEM-X DEMs. Background: Mosaic of two Landsat-8 „Natural Color“ images, acquired on September 16, 2015 @USGS. 
Table S2: Ground range resolution $\Delta \boldsymbol{x}_{\boldsymbol{G R}}$, azimuth resolution $\Delta \boldsymbol{x}_{\boldsymbol{A Z}}$ and image resolution $\Delta \boldsymbol{x}$ used in Formula 1 (S2) for calculating velocity errors. For most of the sensors $\Delta \mathbf{x}_{\mathbf{G R}}$ is coarser than $\Delta \mathbf{x}_{\mathbf{A Z}}$, except for Sentinel-1a that has a coarser resolution in azimuth direction and TSX/TDX which have fairly equal resolutions in both directions. In order to make a conservative estimate of velocity errors, always 5 the coarser resolution value was chosen to be $\Delta \mathbf{x}$.

\begin{tabular}{llll} 
Sensor & $\Delta x_{G R}[\mathrm{~m}]$ & $\Delta x_{A Z}[\mathrm{~m}]$ & $\Delta x[\mathrm{~m}]$ \\
\hline AMI SAR (ERS-1/2) & 20 & 4 & 20 \\
R1 (Radarsat 1) & 20 & 4 & 20 \\
ASAR (Envisat) & 17 & 4 & 17 \\
PALSAR (ALOS) & 7 & 3 & 7 \\
TSX/TDX(TerraSAR-X/TanDEM-X) & 2 & 2 & 2 \\
S1 (Sentinel-1a) & 3 & 14 & 14
\end{tabular}


Table S3: Uncertainty $\sigma_{V}$ of processed velocity fields and proportion of removed velocity measurements by the filter of Burgess et al. (2012). Date: Mean date of SAR acquisitions; $\Delta \boldsymbol{t}$ : Time interval in days between repeat SAR acquisitions; $\boldsymbol{\sigma}_{V}^{\boldsymbol{C}}$ : Uncertainty of image coregistration; $\boldsymbol{\sigma}_{V}^{T}$ : Uncertainty of intensity tracking processing; ERS velocity fields with $\Delta t \leq 3 \mathrm{~d}: \boldsymbol{\sigma}_{V}=\boldsymbol{\sigma}_{V}^{\boldsymbol{C}}$. The percentage of filtered velocities is listed for a reference area on the tongue of Fleming Glacier (Fig. S.1) and each complete velocity field. The table is continued 5 on the next pages.

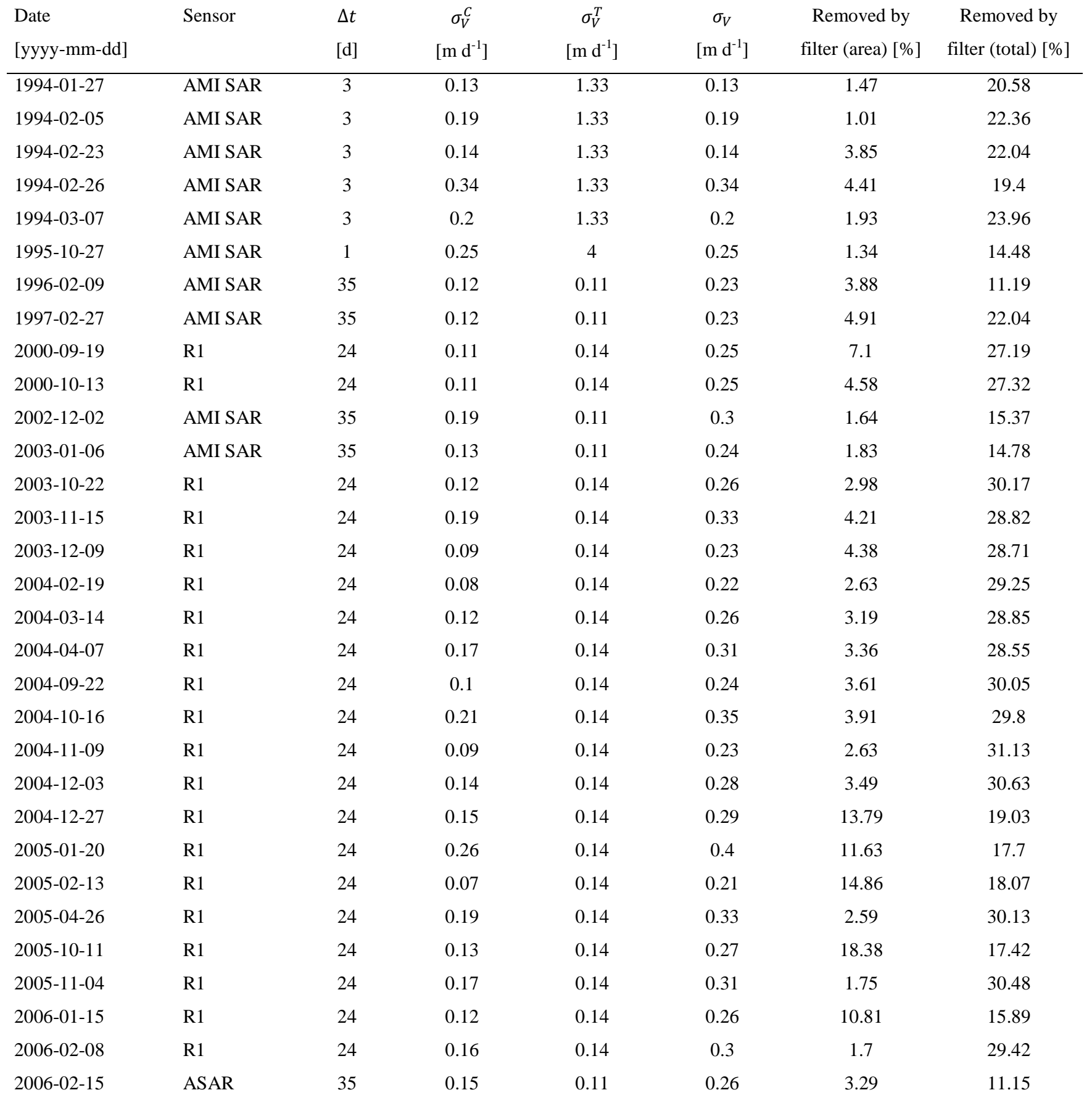




\begin{tabular}{|c|c|c|c|c|c|c|c|}
\hline $\begin{array}{l}\text { Date } \\
\text { [yyyy-mm-dd] }\end{array}$ & Sensor & $\begin{array}{l}\Delta t \\
{[\mathrm{~d}]}\end{array}$ & $\begin{array}{c}\sigma_{V}^{C} \\
{\left[\mathrm{~m} \mathrm{~d}^{-1}\right]}\end{array}$ & $\begin{array}{c}\sigma_{V}^{T} \\
{\left[\mathrm{~m} \mathrm{~d}^{-1}\right]}\end{array}$ & $\begin{array}{c}\sigma_{V} \\
{\left[\mathrm{~m} \mathrm{~d}^{-1}\right]}\end{array}$ & $\begin{array}{c}\text { Removed by } \\
\text { filter (area) [\%] }\end{array}$ & $\begin{array}{c}\text { Removed by } \\
\text { filter (total) [\%] }\end{array}$ \\
\hline $2006-03-04$ & R1 & 24 & 0.06 & 0.14 & 0.2 & 1.23 & 30.23 \\
\hline 2006-03-28 & $\mathrm{R} 1$ & 24 & 0.23 & 0.14 & 0.37 & 1.27 & 30.25 \\
\hline 2006-04-21 & R1 & 24 & 0.17 & 0.14 & 0.31 & 1.25 & 30.13 \\
\hline $2006-05-31$ & ASAR & 35 & 0.09 & 0.11 & 0.2 & 3.35 & 8.81 \\
\hline 2006-07-05 & ASAR & 35 & 0.11 & 0.11 & 0.22 & 3.2 & 8.74 \\
\hline 2006-07-18 & PALSAR & 46 & 0.06 & 0.03 & 0.09 & 27.76 & 12.77 \\
\hline 2006-08-09 & ASAR & 35 & 0.14 & 0.11 & 0.25 & 3.82 & 8.82 \\
\hline 2006-11-03 & AMI SAR & 35 & 0.18 & 0.11 & 0.29 & 3.1 & 9.16 \\
\hline 2007-04-10 & ASAR & 35 & 0.17 & 0.11 & 0.28 & 11.26 & 8.89 \\
\hline $2007-05-15$ & ASAR & 35 & 0.06 & 0.11 & 0.17 & 1.29 & 13.54 \\
\hline $2007-05-16$ & ASAR & 35 & 0.09 & 0.11 & 0.2 & 3.44 & 9.7 \\
\hline 2007-06-19 & ASAR & 35 & 0.05 & 0.11 & 0.16 & 3.44 & 12.76 \\
\hline $2007-06-20$ & ASAR & 35 & 0.08 & 0.11 & 0.19 & 1.33 & 11.22 \\
\hline $2007-07-25$ & ASAR & 35 & 0.05 & 0.11 & 0.16 & 3.92 & 11.41 \\
\hline $2007-08-28$ & ASAR & 35 & 0.1 & 0.11 & 0.21 & 1.41 & 13.03 \\
\hline 2007-08-29 & ASAR & 35 & 0.13 & 0.11 & 0.24 & 4.08 & 10.76 \\
\hline 2007-10-02 & ASAR & 35 & 0.08 & 0.11 & 0.19 & 1.45 & 11.25 \\
\hline $2007-10-03$ & ASAR & 35 & 0.11 & 0.11 & 0.22 & 4.25 & 10.71 \\
\hline $2007-10-23$ & PALSAR & 46 & 0.05 & 0.03 & 0.08 & 20.19 & 12.04 \\
\hline 2007-11-06 & ASAR & 35 & 0.06 & 0.11 & 0.17 & 1.63 & 13.35 \\
\hline 2008-01-05 & $\mathrm{R} 1$ & 24 & 0.2 & 0.14 & 0.34 & 1.95 & 29.79 \\
\hline $2008-04-30$ & ASAR & 35 & 0.11 & 0.11 & 0.22 & 5.52 & 11.36 \\
\hline $2008-06-03$ & ASAR & 35 & 0.08 & 0.11 & 0.19 & 1.97 & 14.19 \\
\hline 2008-07-08 & ASAR & 35 & 0.06 & 0.11 & 0.17 & 2.05 & 14.17 \\
\hline $2008-08-12$ & ASAR & 35 & 0.08 & 0.11 & 0.19 & 2.37 & 13.69 \\
\hline 2008-09-16 & ASAR & 35 & 0.08 & 0.11 & 0.19 & 2.22 & 14.31 \\
\hline $2008-10-21$ & ASAR & 35 & 0.07 & 0.11 & 0.18 & 2.45 & 14.51 \\
\hline 2009-02-06 & PALSAR & 46 & 0.15 & 0.03 & 0.18 & 26.83 & 14.54 \\
\hline 2009-04-14 & ASAR & 35 & 0.22 & 0.11 & 0.33 & 6.95 & 7.04 \\
\hline 2009-07-29 & ASAR & 35 & 0.09 & 0.11 & 0.2 & 6.57 & 11.92 \\
\hline 2009-09-02 & ASAR & 35 & 0.09 & 0.11 & 0.2 & 6.44 & 10.57 \\
\hline 2009-10-07 & ASAR & 35 & 0.09 & 0.11 & 0.2 & 6.63 & 10.48 \\
\hline 2010-02-08 & ASAR & 35 & 0.08 & 0.11 & 0.19 & 4.69 & 11.03 \\
\hline 2010-02-11 & ASAR & 35 & 0.19 & 0.11 & 0.3 & 0.02 & 5.38 \\
\hline 2010-03-31 & ASAR & 35 & 0.09 & 0.11 & 0.2 & 5.16 & 9.52 \\
\hline
\end{tabular}




\begin{tabular}{|c|c|c|c|c|c|c|c|}
\hline $\begin{array}{l}\text { Date } \\
\text { [yyyy-mm-dd] }\end{array}$ & Sensor & $\begin{array}{l}\Delta t \\
{[\mathrm{~d}]}\end{array}$ & $\begin{array}{c}\sigma_{V}^{C} \\
{\left[\mathrm{~m} \mathrm{~d}^{-1}\right]}\end{array}$ & $\begin{array}{c}\sigma_{V}^{T} \\
{\left[\mathrm{~m} \mathrm{~d}^{-1}\right]}\end{array}$ & $\begin{array}{c}\sigma_{V} \\
{\left[\mathrm{~m} \mathrm{~d}^{-1}\right]}\end{array}$ & $\begin{array}{c}\text { Removed by } \\
\text { filter (area) [\%] }\end{array}$ & $\begin{array}{c}\text { Removed by } \\
\text { filter (total) [\%] }\end{array}$ \\
\hline $2010-05-05$ & ASAR & 35 & 0.1 & 0.11 & 0.21 & 5.49 & 11.38 \\
\hline 2010-06-09 & ASAR & 35 & 0.08 & 0.11 & 0.19 & 5.29 & 11.08 \\
\hline $2010-07-14$ & ASAR & 35 & 0.09 & 0.11 & 0.2 & 5.39 & 11.51 \\
\hline $2010-08-18$ & ASAR & 35 & 0.1 & 0.11 & 0.21 & 5.87 & 11.49 \\
\hline 2010-09-22 & ASAR & 35 & 0.09 & 0.11 & 0.2 & 6.04 & 11.49 \\
\hline $2010-10-27$ & TSX/TDX & 33 & 0.01 & 0.01 & 0.02 & 3.7 & 12.01 \\
\hline $2010-10-31$ & PALSAR & 46 & 0.33 & 0.03 & 0.36 & 28.43 & 10.62 \\
\hline $2010-11-18$ & TSX/TDX & 11 & 0.02 & 0.04 & 0.06 & 4.06 & 11.68 \\
\hline 2011-05-10 & AMI SAR & 3 & 0.25 & 1.33 & 0.25 & 2.52 & 19.79 \\
\hline $2011-06-27$ & AMI SAR & 3 & 0.36 & 1.33 & 0.36 & 6.46 & 20.24 \\
\hline 2011-10-02 & TSX/TDX & 11 & 0.02 & 0.04 & 0.06 & 2.94 & 8.23 \\
\hline 2011-11-15 & TSX/TDX & 11 & 0.03 & 0.04 & 0.07 & 5.02 & 10.86 \\
\hline $2011-12-29$ & TSX/TDX & 11 & 0.01 & 0.04 & 0.05 & 6.47 & 10.21 \\
\hline 2012-03-15 & TSX/TDX & 11 & 0.02 & 0.04 & 0.06 & 3.55 & 9.64 \\
\hline 2012-04-06 & TSX/TDX & 11 & 0.02 & 0.04 & 0.06 & 4.56 & 10.76 \\
\hline 2012-04-17 & TSX/TDX & 11 & 0.02 & 0.04 & 0.06 & 3.66 & 9.34 \\
\hline 2012-05-31 & TSX/TDX & 11 & 0.03 & 0.04 & 0.07 & 4.14 & 10.34 \\
\hline $2012-06-11$ & TSX/TDX & 11 & 0.01 & 0.04 & 0.05 & 4.01 & 10.41 \\
\hline $2012-07-25$ & TSX/TDX & 11 & 0.02 & 0.04 & 0.06 & 1.69 & 10.52 \\
\hline 2012-09-07 & TSX/TDX & 11 & 0.02 & 0.04 & 0.06 & 4.53 & 10.29 \\
\hline $2012-10-21$ & TSX/TDX & 11 & 0.02 & 0.04 & 0.06 & 4.34 & 10.33 \\
\hline $2012-12-04$ & TSX/TDX & 11 & 0.02 & 0.04 & 0.06 & 3.37 & 9.84 \\
\hline 2013-01-17 & TSX/TDX & 11 & 0.01 & 0.04 & 0.05 & 3.94 & 8.18 \\
\hline 2013-03-13 & TSX/TDX & 11 & 0.03 & 0.04 & 0.07 & 3.8 & 9.63 \\
\hline $2013-03-23$ & TSX/TDX & 11 & 0.08 & 0.04 & 0.12 & 2.19 & 6.64 \\
\hline 2013-04-15 & TSX/TDX & 11 & 0.03 & 0.04 & 0.07 & 3.47 & 10.15 \\
\hline 2013-06-09 & TSX/TDX & 11 & 0.02 & 0.04 & 0.06 & 2.56 & 8.79 \\
\hline 2013-06-20 & TSX/TDX & 11 & 0.02 & 0.04 & 0.06 & 3.94 & 8.76 \\
\hline 2013-07-01 & TSX/TDX & 11 & 0.02 & 0.04 & 0.06 & 2.37 & 8.48 \\
\hline 2013-07-12 & TSX/TDX & 11 & 0.02 & 0.04 & 0.06 & 2.2 & 8.48 \\
\hline $2013-11-20$ & TSX/TDX & 11 & 0.04 & 0.04 & 0.08 & 0.71 & 5.77 \\
\hline $2013-12-13$ & TSX/TDX & 11 & 0.03 & 0.04 & 0.07 & 4.25 & 8.29 \\
\hline $2013-12-24$ & TSX/TDX & 11 & 0.02 & 0.04 & 0.06 & 3.57 & 8.02 \\
\hline 2014-01-26 & TSX/TDX & 11 & 0.01 & 0.04 & 0.05 & 3.2 & 7.72 \\
\hline $2014-08-23$ & TSX/TDX & 11 & 0.02 & 0.04 & 0.06 & 4.67 & 10.98 \\
\hline
\end{tabular}




\begin{tabular}{|c|c|c|c|c|c|c|c|}
\hline $\begin{array}{l}\text { Date } \\
\text { [yyyy-mm-dd] }\end{array}$ & Sensor & $\begin{array}{l}\Delta t \\
{[\mathrm{~d}]}\end{array}$ & $\begin{array}{c}\sigma_{V}^{C} \\
{\left[\mathrm{~m} \mathrm{~d}^{-1}\right]}\end{array}$ & $\begin{array}{c}\sigma_{V}^{T} \\
{\left[\mathrm{~m} \mathrm{~d}^{-1}\right]}\end{array}$ & $\begin{array}{c}\sigma_{V} \\
{\left[\mathrm{~m} \mathrm{~d}^{-1}\right]}\end{array}$ & $\begin{array}{c}\text { Removed by } \\
\text { filter (area) [\%] }\end{array}$ & $\begin{array}{c}\text { Removed by } \\
\text { filter (total) [\%] }\end{array}$ \\
\hline 2014-09-03 & TSX/TDX & 11 & 0.03 & 0.04 & 0.07 & 4.52 & 10.36 \\
\hline 2014-12-11 & TSX/TDX & 11 & 0.01 & 0.04 & 0.05 & 4.05 & 6.79 \\
\hline 2015-01-24 & TSX/TDX & 11 & 0.03 & 0.04 & 0.07 & 2.2 & 9.04 \\
\hline 2015-09-03 & S1 & 12 & 0.06 & 0.23 & 0.29 & 2.47 & 19.85 \\
\hline 2015-09-15 & S1 & 12 & 0.05 & 0.23 & 0.28 & 2.51 & 20.36 \\
\hline $2015-10-21$ & S1 & 12 & 0.15 & 0.23 & 0.38 & 2.51 & 19.74 \\
\hline 2015-12-08 & S1 & 12 & 0.11 & 0.23 & 0.34 & 2.03 & 12.42 \\
\hline $2015-12-20$ & S1 & 12 & 0.07 & 0.23 & 0.3 & 2.13 & 13.99 \\
\hline 2016-01-01 & S1 & 12 & 0.09 & 0.23 & 0.32 & 2.21 & 13.15 \\
\hline 2016-01-13 & S1 & 12 & 0.05 & 0.23 & 0.28 & 2.08 & 13.79 \\
\hline $2016-01-25$ & $\mathrm{~S} 1$ & 12 & 0.08 & 0.23 & 0.31 & 2.18 & 13.59 \\
\hline 2016-02-06 & S1 & 12 & 0.08 & 0.23 & 0.31 & 2.15 & 12.85 \\
\hline 2016-02-18 & S1 & 12 & 0.08 & 0.23 & 0.31 & 2.1 & 13.56 \\
\hline 2016-03-01 & $\mathrm{S} 1$ & 12 & 0.09 & 0.23 & 0.32 & 2.15 & 12.63 \\
\hline 2016-03-13 & S1 & 12 & 0.08 & 0.23 & 0.31 & 2.11 & 13.58 \\
\hline 2016-04-06 & S1 & 12 & 0.09 & 0.23 & 0.32 & 2.01 & 12.64 \\
\hline 2016-04-18 & S1 & 12 & 0.07 & 0.23 & 0.3 & 2.12 & 13.43 \\
\hline 2016-06-05 & $\mathrm{S} 1$ & 12 & 0.12 & 0.23 & 0.35 & 1.97 & 13.02 \\
\hline 2016-07-23 & $\mathrm{S} 1$ & 12 & 0.1 & 0.23 & 0.33 & 2.09 & 12.36 \\
\hline 2016-08-04 & $\mathrm{S} 1$ & 12 & 0.08 & 0.23 & 0.31 & 2.07 & 12.51 \\
\hline 2016-08-16 & S1 & 12 & 0.06 & 0.23 & 0.29 & 2.17 & 14.7 \\
\hline
\end{tabular}




\section{S3 Uncertainty estimation of variables for the hydrostatic height anomaly calculations and assessment of error propagation}

In order to assess the propagation of uncertainties for the calculation of hydrostatic height anomalies, we estimated the error of each variable of Formula 2. The accuracy of the ATM elevations was estimated to be $\pm 0.2 \mathrm{~m}$. The overall uncertainty of

5 the EIGEN-6C4 geoid is $0.24 \mathrm{~m}$ (http://icgem.gfz-potsdam.de/ICGEM/). Accounting for an unknown additional error induced by kriging of the geoid values, we assumed a total accuracy of $\pm 0.5 \mathrm{~m}$ for $e$. Following the recommendation of the CReSIS Radar Depth Sounders (RDS) user guide (ftp://data.cresis.ku.edu/data/rds/rds readme.pdf) we defined the error of $H_{i}$ as the sum of the RMS error of the sensor`s range resolution and the RMS error of the dielectric. Depending on the sensor, the uncertainty of $H_{i}$ varies between $\sim 6$ and $\sim 14 \mathrm{~m}$ for an ice thickness of $750 \mathrm{~m}$, which is the approx. mean ice

10 thickness in the vicinity of the current grounding line measured on our OIB profiles. For $\rho_{i}$ we used a value of $917 \mathrm{~kg} \mathrm{~m}^{-3}$, which is the standard density of pure ice (Benn and Evans, 2013). However, since impurities in the ice can cause this value to vary by around $\pm 5 \mathrm{~kg} \mathrm{~m}^{-3}$ (Griggs and Bamber, 2011), we chose this rate to be the uncertainty of $\rho_{i}$. The global mean density of sea water is $1027 \mathrm{~kg} \mathrm{~m}^{-3}$, but this value can vary locally. According to Griggs and Bamber (2011) we therefore assumed an error of $\pm 5 \mathrm{~kg} \mathrm{~m}^{-3}$ for $\rho_{w}$. The firn density correction factor for pure glacier ice is 0 . In situ values of about $10 \mathrm{~m}$

15 have been measured for $\delta$ on Larsen C Ice Shelf (Griggs and Bamber, 2009) and firn density correction factors $>20 \mathrm{~m}$ have been reported for areas of convergent flow on the Ross Ice Shelf (Bamber and Bentley, 1994). Modelled firn densities (van den Broeke, Michiel et al., 2008) indicate a firn correction factor of $\sim 17 \pm 4 \mathrm{~m}$ for the glacier tongue of the Airy-Rotz-SellerFleming glacier system. . In order to quantify the total error of $\Delta e$ and to consider the propagation of uncertainties, we run a Monte Carlo simulation based on Formula 1 and 2 with 100.000 runs. For all possible sensor-depending errors of $\mathrm{H}_{\mathrm{i}}=750 \mathrm{~m}$

20 the Monte Carlo simulation yielded a standard deviation of $\sim 6 \mathrm{~m}$ for $\Delta \mathrm{e}$. Thus we assumed the total uncertainty of $\Delta \mathrm{e}$ to be $\sim 6 \mathrm{~m}$. Consequently, we assigned locations on our OIB and PIB profiles to be freely floating ice, if the calculated values of $\Delta \mathrm{e}$ lay within this range. In the vicinity of the grounding zone the TDX global DEM has a minimum slope of $1^{\circ}$, and therefore we estimate the uncertainty in the horizontal position of the transition from grounded to freely floating ice to be $\sim 350 \mathrm{~m}$. 


\section{S4 Penetration bias correction of TSX/TDX 2011-2014 elevation change rates}

Figure S4 a-c: Penetration bias correction of TSX/TDX 2011-2014 elevation change rates

(a) Comparison of yearly elevation change rates obtained from OIB ATM LiDAR measurements (2011-11-17/2014-11-10) and TSX/TDX DEMs (2011-11-21/2014-11-03) after vertical registration of the TSX/TDX DEMs. Data is plotted against absolute ellipsoidal elevations

5 from the resampled Bedmap 2 DEM (Fretwell et al., 2013). Grey dots: elevation change rates between 2011 and 2014 from OIB ATM. Black line: cubic function fitted to the OIB ATM measurements. Light blue dots: elevation change rates between 2011 and 2014 from TSX/TDX. Blue line: cubic function fitted to the TSX/TDX measurements

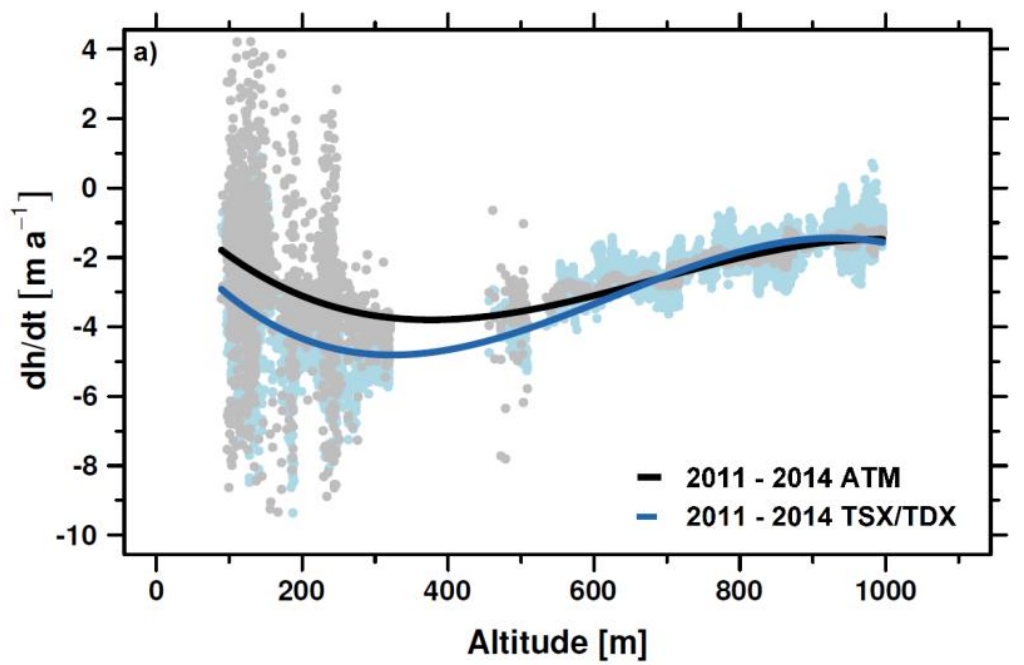

10 (b) Penetration bias correction model for TSX/TDX change rates. Data is plotted against absolute ellipsoidal elevations from the resampled Bedmap 2 DEM (Fretwell et al., 2013). Black dots: differences between TSX/TDX elevation change rates ( $\left.r_{\text {DEM }}\right)$ and OIB ATM rates $\left(\mathrm{r}_{\mathrm{ATM}}\right)$. Green line: local polynomial model fitted to the measurements.

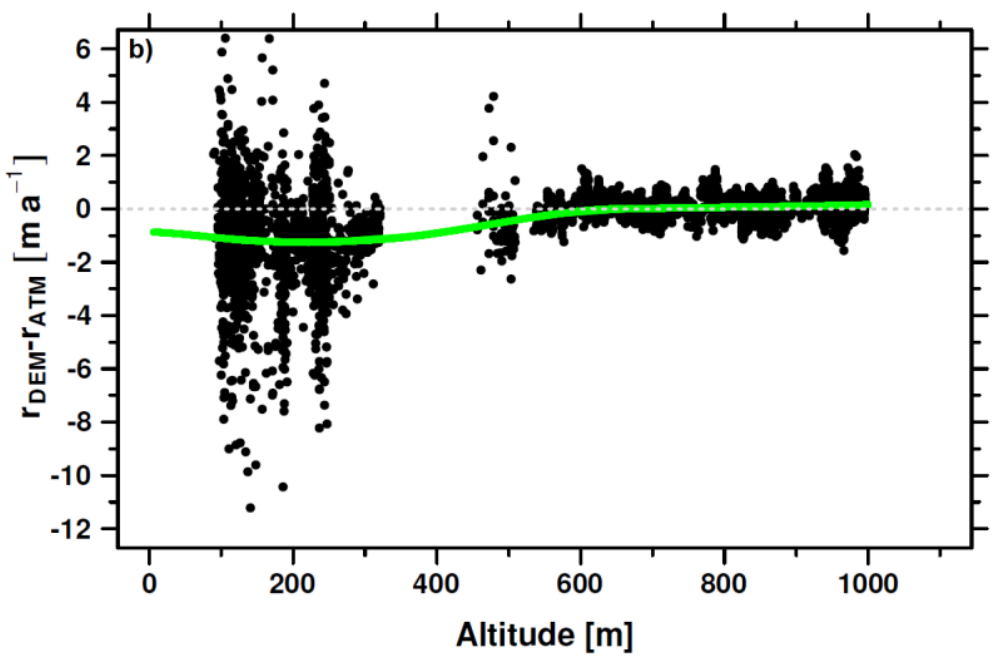


(c) Comparison of yearly elevation change rates obtained from OIB ATM LiDAR measurements (2011-11-17/2014-11-10) and TSX/TDX DEMs (2011-11-21/2014-11-03) after vertical registration and penetration depth bias correction of the TSX/TDX elevation change map. Data is plotted against absolute ellipsoidal elevations from the resampled Bedmap 2 DEM (Fretwell et al., 2013). Grey dots: elevation change rates between 2011 and 2014 from OIB ATM. Black line: cubic function fitted to the OIB ATM measurements. Light blue dots:

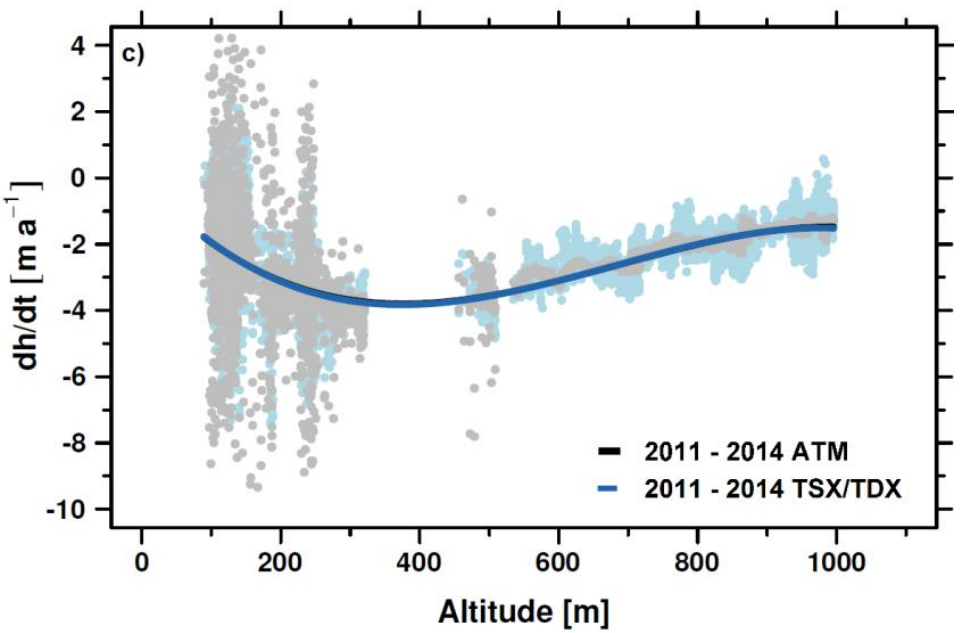

(d) Comparison of median filtered backscatter values of TSX/TDX acquisitions on 2011-11-21 and 2014-11-03. Data is plotted against absolute ellipsoidal elevations from the resampled Bedmap 2 DEM (Fretwell et al., 2013). Light pink dots: backscatter of the master image on 2011-11-21. Brown line: cubic function fitted to the 2011-11-21 backscatter values. Light blue dots: backscatter of the master image on 2014-11-03. Dark blue line: cubic function fitted to the 2014-11-03 backscatter values.

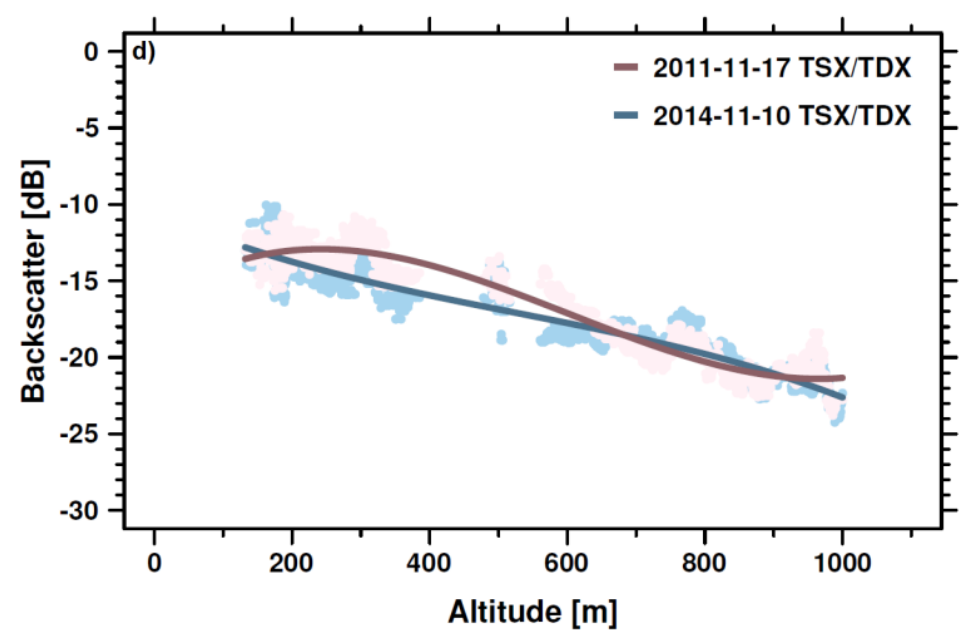


(e) Comparison of yearly elevation change rates along a validation track of OIB ATM LiDAR measurements (2011-11-17/2014-11-10) (Figure 4) and elevation change rates from the penetration depth corrected differential TSX/TDX DEM (2011-11-21/2014-11-03). Data is plotted against absolute ellipsoidal elevations from the resampled Bedmap 2 DEM (Fretwell et al., 2013). Grey dots: elevation change rates between 2011 and 2014 from OIB ATM. Black line: cubic function fitted to the OIB ATM measurements. Light blue dots: elevation change rates between 2011 and 2014 from TSX/TDX. Blue line: cubic function fitted to the TSX/TDX measurements

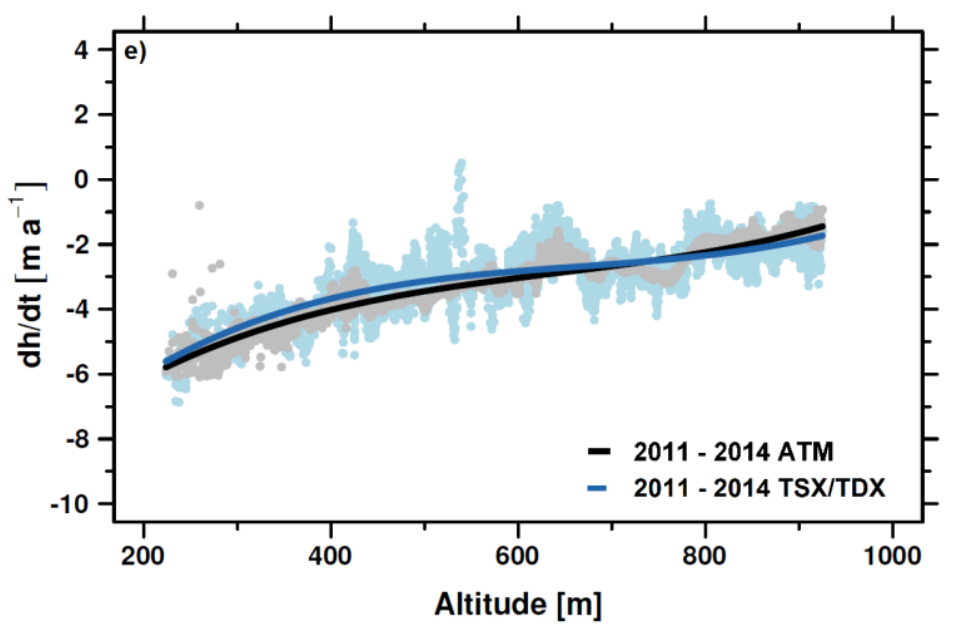




\section{S5 Results of the hydrostatic height anomaly calculations}

Figure S5 a-e: Fulfillment of the hydrostatic equilibrium assumption from hydrostatic height anomaly calculations along PIB and OIB profiles. Profiles are to read from left to right (in upstream direction). Dates of PIB and OIB flights: a) 2002-11-26, b) 2004-11-18, c) 2011-11-17, d) 2014-11-16, e) 2014-11-10. Purple dots: PIB/OIB ice surface/bottom elevations. Ice surface elevation is taken from

5 PIB/OIB ATM measurements and ice bottom elevation is calculated by subtracting OIB/PIB ice thickness from ice surface elevation. Brown line: Bedrock elevation from Huss and Farinotti, 2014. Yellow line: Bedrock elevation from Bedmap 2 (Fretwell et al., 2013 ). Red and blue dots: calculated ice surface elevation in hydrostatic equilibrium $\boldsymbol{e}_{\boldsymbol{h} \boldsymbol{e}}$ and information on hydrostatic equilibrium (blue: freely floating ice, red: grounded ice)

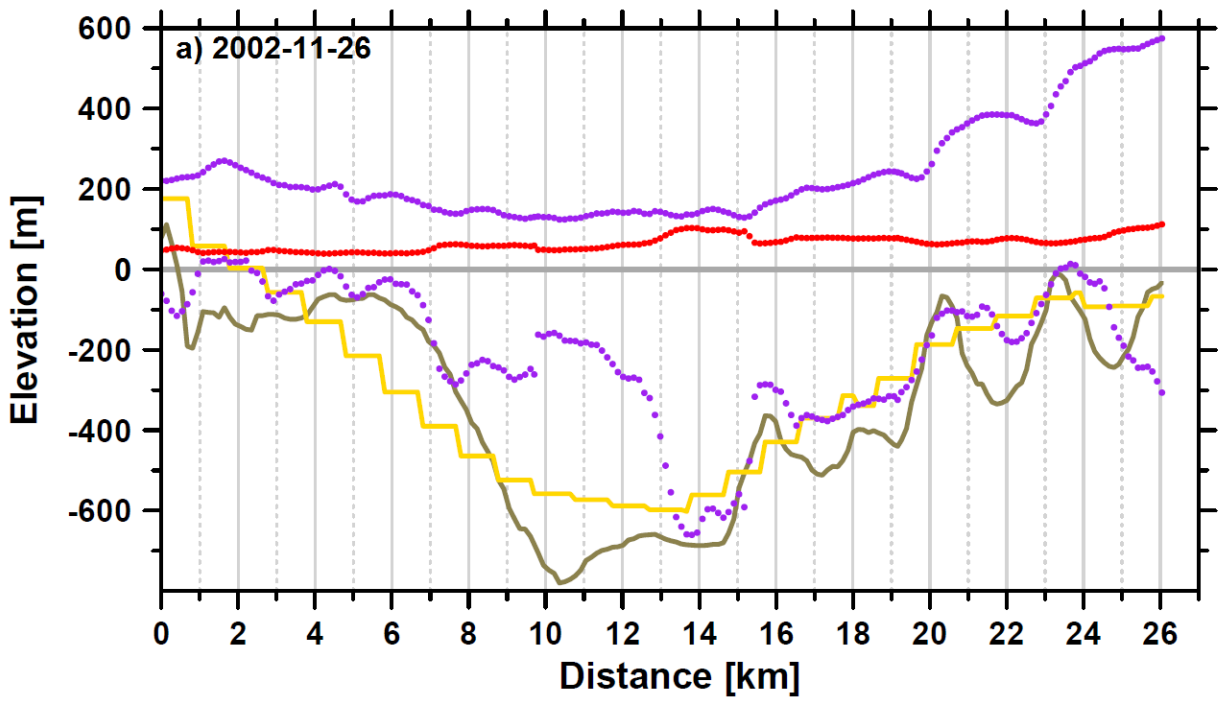

10

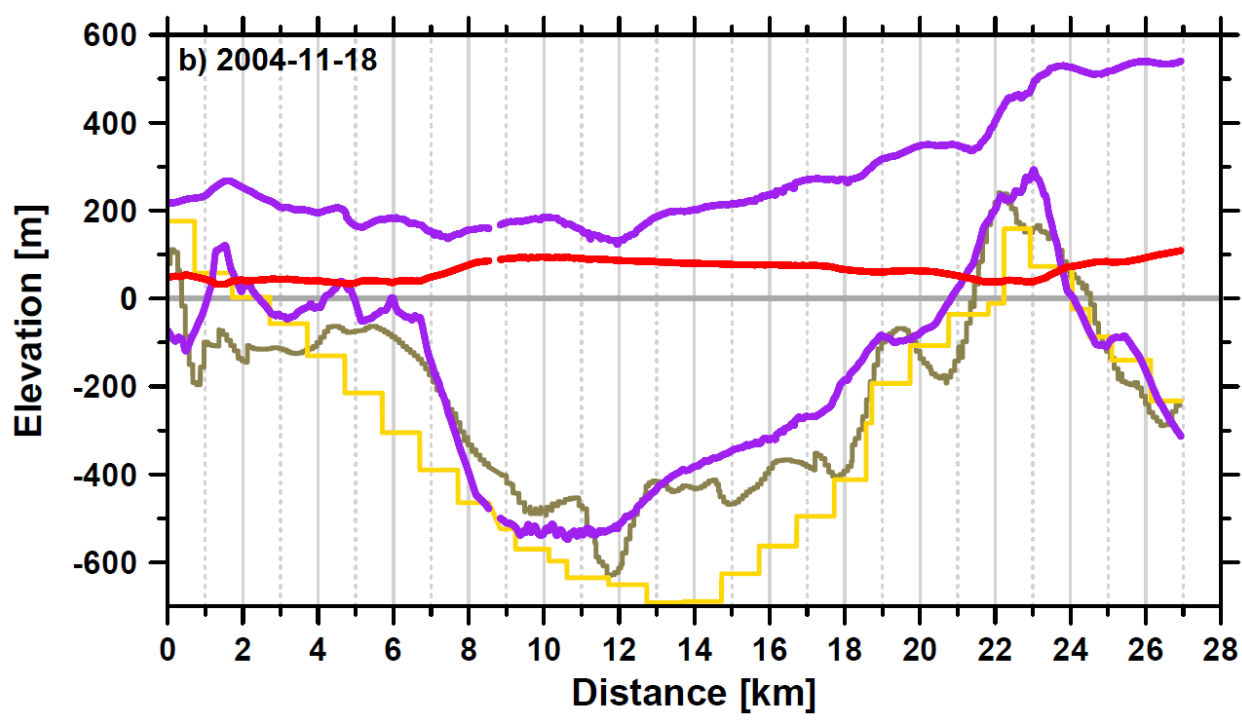

Ice Surface/Bottom elevation (OIB)

Elevation in $\mathrm{HE}$ (grounded)

Elevation in $\mathrm{HE}$ (freely floating)

Bedrock (Huss \& Farionotti 2014)

Bedrock (BEDMAP 2)
Ice Surface/Bottom elevation (OIB)

Elevation in HE (grounded)

Elevation in HE (freely floating)

Bedrock (Huss \& Farionotti 2014)

Bedrock (BEDMAP 2) 


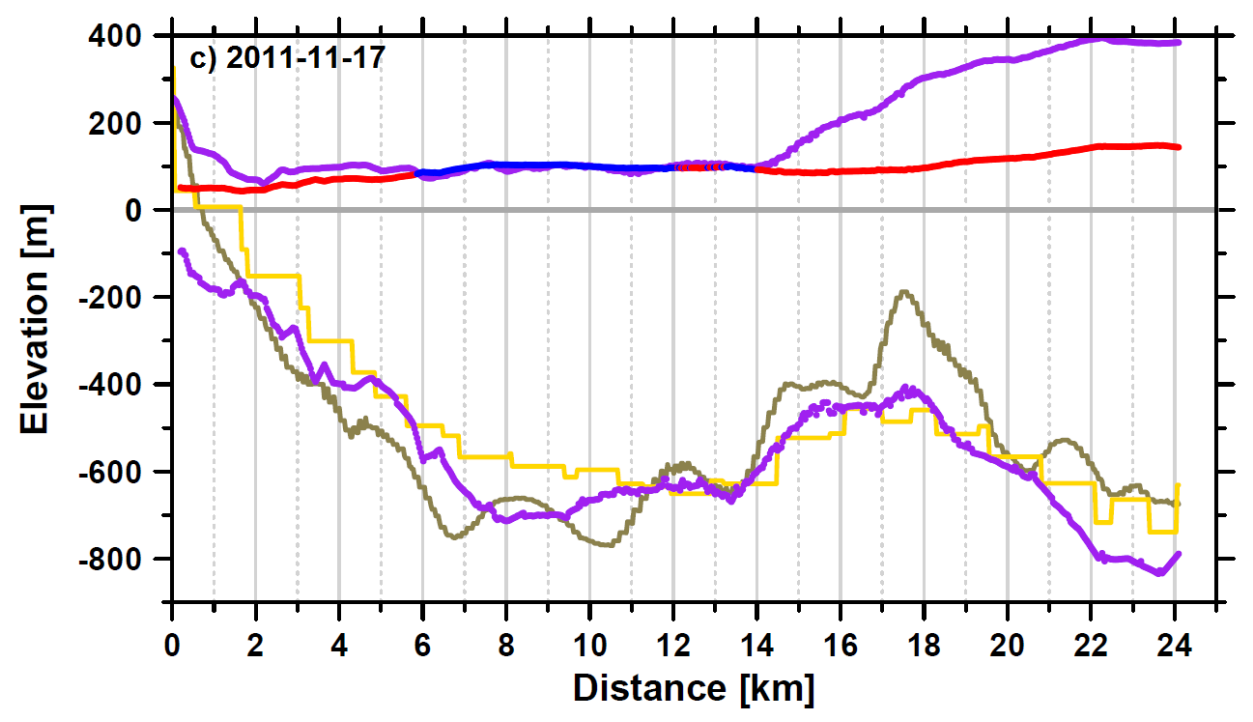

Ice Surface/Bottom elevation (OIB) Elevation in HE (grounded)

Elevation in HE (freely floating)

Bedrock (Huss \& Farionotti 2014)

Bedrock (BEDMAP 2)

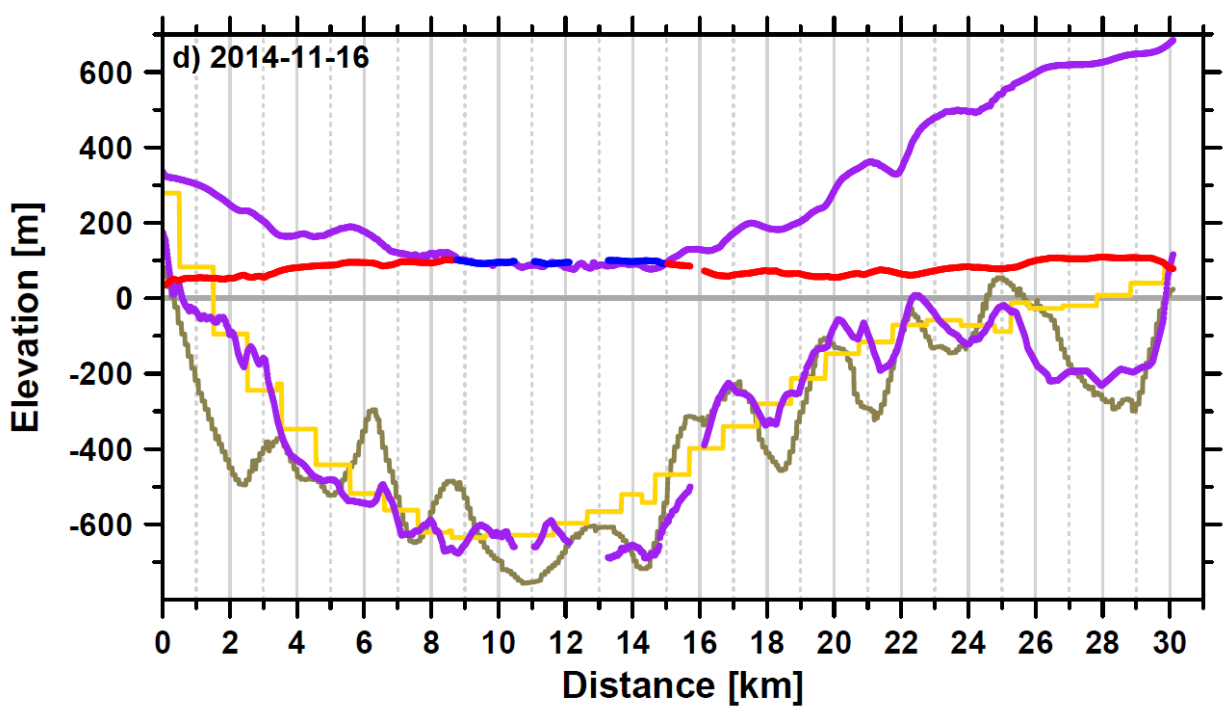

Ice Surface/Bottom elevation (OIB)

Elevation in HE (grounded)

Elevation in $\mathrm{HE}$ (freely floating)

Bedrock (Huss \& Farionotti 2014)

Bedrock (BEDMAP 2) 


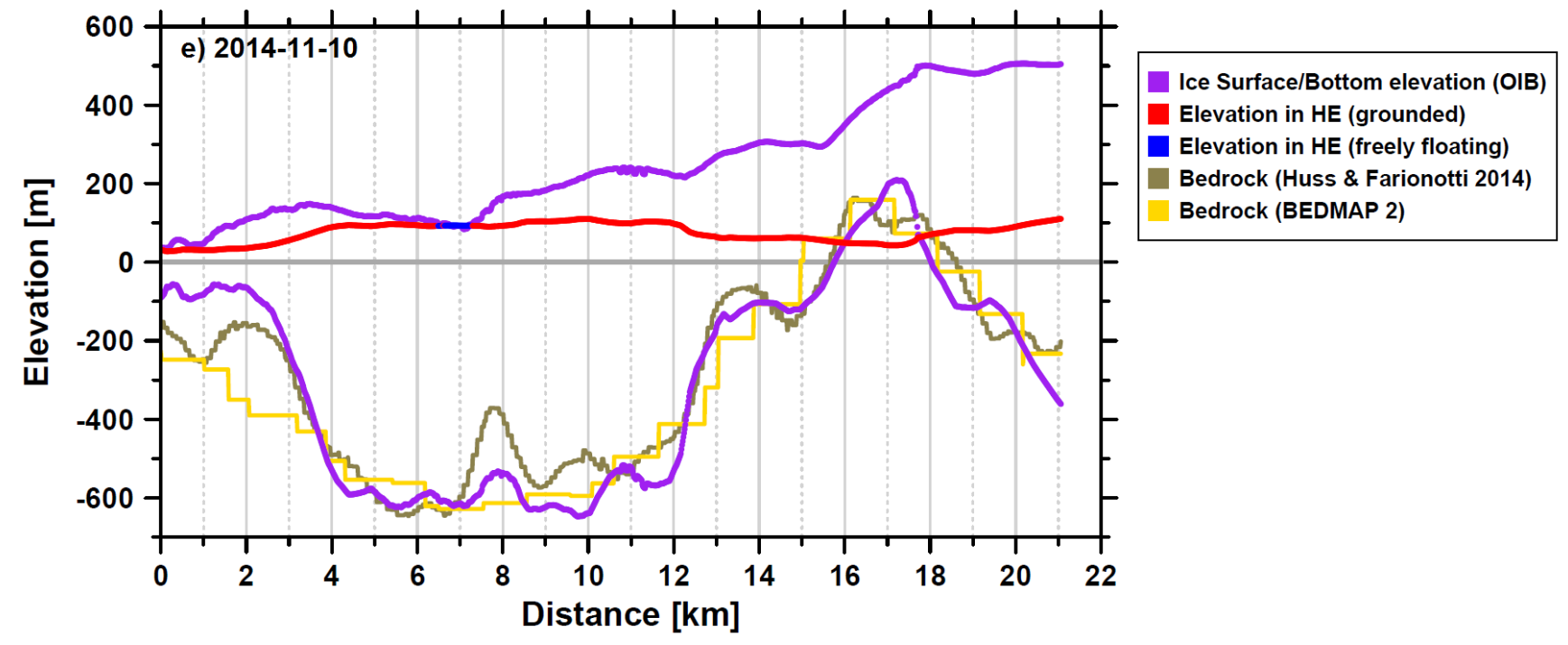


S6 Estimation of grounding line positions along profiles of surface velocity, bedrock topography, ice elevations and hydrostatic height anomalies

Figure S6 a-d: Estimated grounding line positions on profiles a-d (for location see Fig. 6) based on surface velocities and elevation change rates from TDX (black line). Distances for Fig. S6 a-d are relative to the 1996 grounding line. F: Front, GL: Grounding Line.

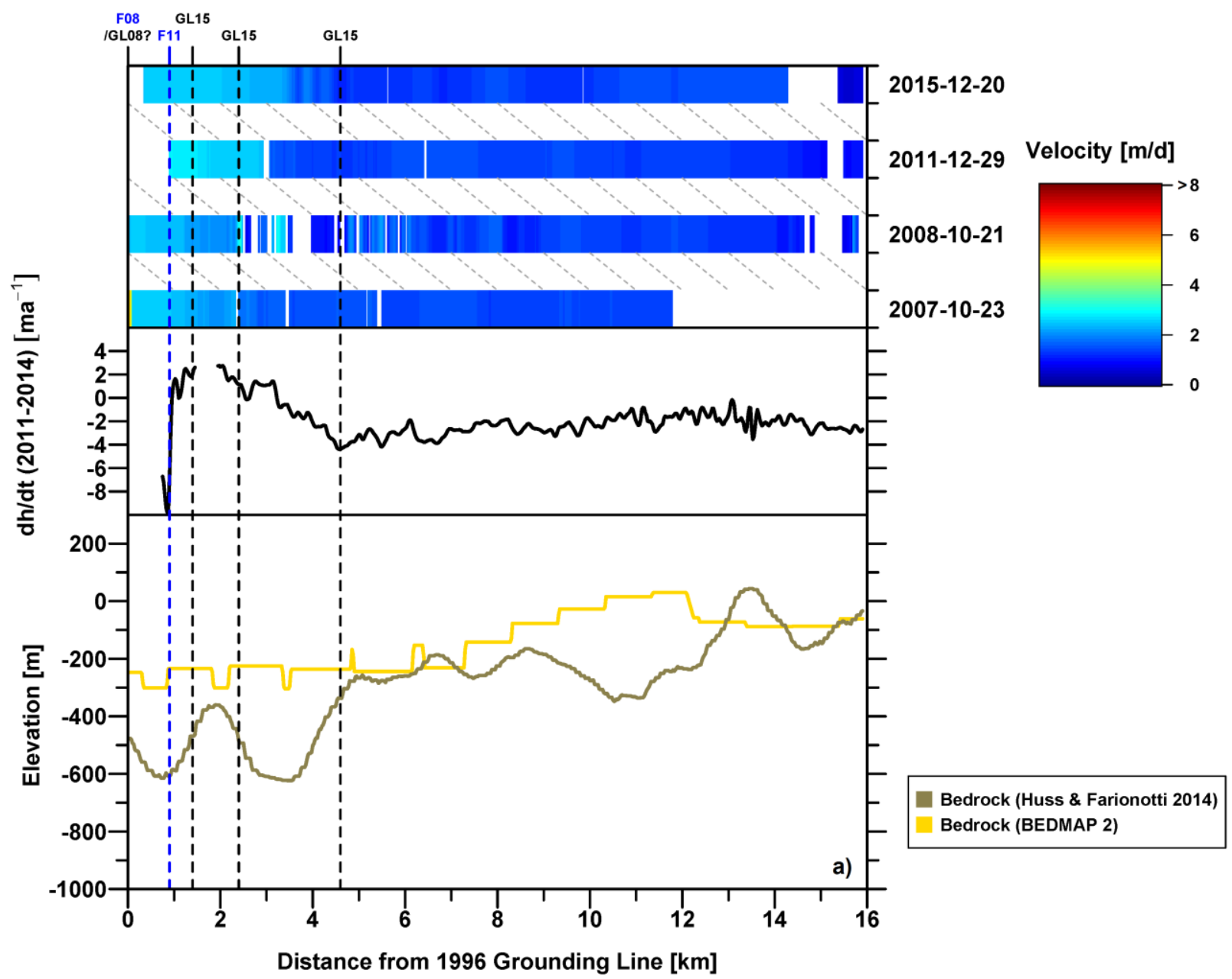

Figure S6 a exhibits that in contrast to Fleming Glacier, on Airy Glacier velocity data extracted along Profile a (Fig. 6) does not show signs of acceleration between 2007 and 2008. Furthermore in 2008 the front was still located at the 1996 grounding line. Hence, we assume that in 2008 Airy Glacier was still grounded at the 1996 grounding line position. However, in 2011

10 the front had retreated behind the 1996 grounding line. This shows that the grounding line must have had retreated from its 1996 position by this time. An abrupt change in the 2011-2014 TSX/TDX elevation change rates is visible at 4-5 km upstream, which coincides with the edge of the subglacial trough in the bedrock data. A similar extent of accelerated surface 
velocities is visible on the velocity profiles in 2011 and 2015. Hence, this location is likely the recent location of the grounding line. A distinct area of low elevation change rates which is visible on the TSX/TDX dh/dt map (Fig. S7) suggests that the entire Airy Glacier tongue may be currently floating up to $\sim 4 \mathrm{~km}$ upstream of the 1996 grounding line. However, this is in contrast to the buoyancy calculations (Fig. 6, Track 3) which indicate that in 2011 the ice was grounded on a hill $\sim 2 \mathrm{~km}$

5 upstream, which reaches to the subglacial trough. Since we assume that the hydrostatic height anomalies from 2011 are the most reliable source of information for grounding line detection we have, we delineated the recent grounding line accordingly. However, we cannot rule out that the ice which rested on the hill in 2011 is afloat today.

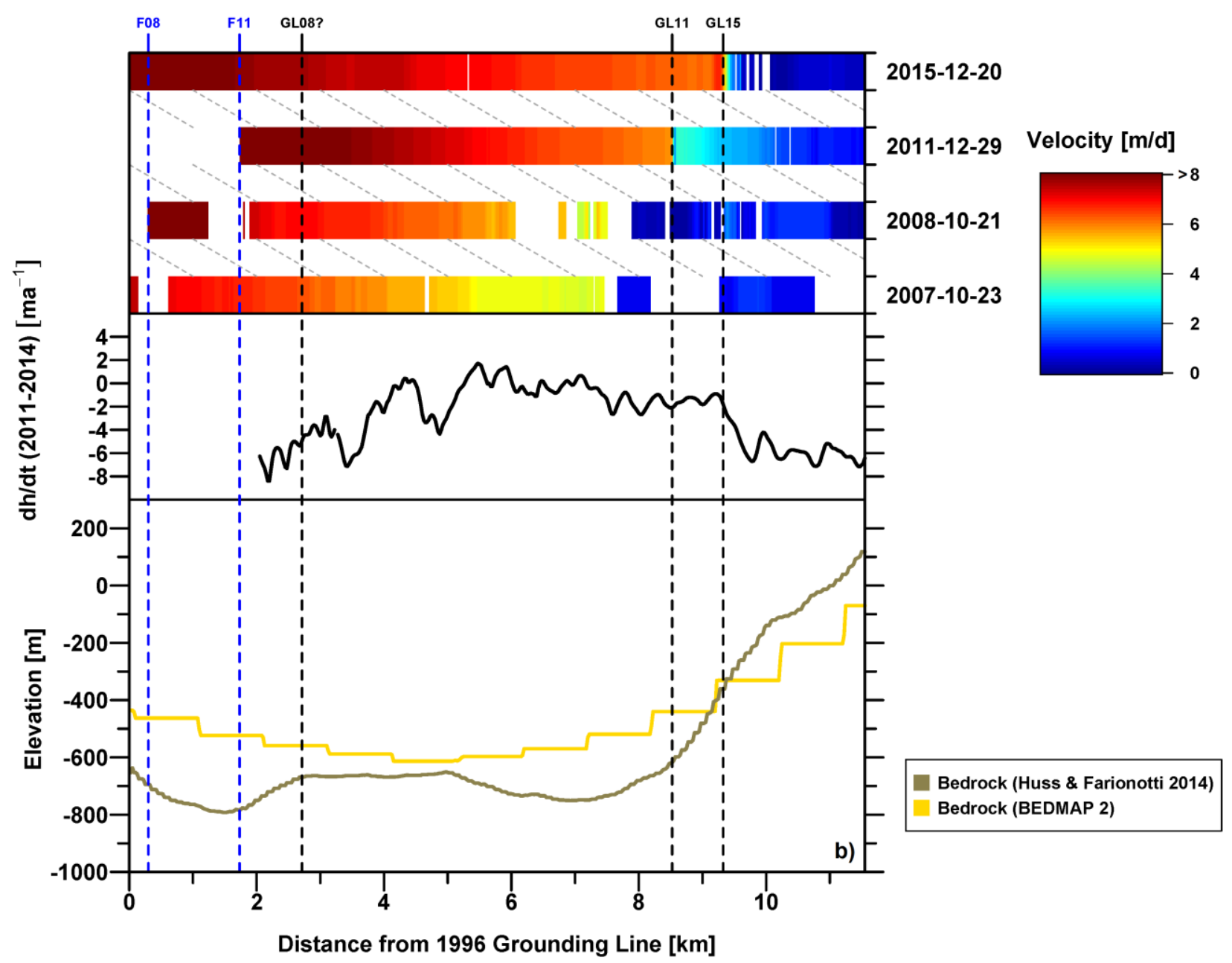

Figure S6 b depicts data extracted along Profile b (Fig. 6), close to the confluence of Fleming and Seller Glacier. Here

velocities show acceleration between 2007 and 2008. While the glacier had accelerated, the glacier front had retreated behind the 1996 grounding line. Hence, in 2008 the grounding line must have been located upstream of the 1996 position. The 
upstream extent of acceleration visible on the velocity profile suggests that in 2008 the grounding line had not retreated as far as in 2011 and 2015, yet. A reasonable estimate would be that the grounding line in 2008 was located on a gentle hill apparent in the bedrock data close to the 2011 front, $\sim 4 \mathrm{~km}$ upstream. However, given the limitations of the modelled bedrock topography (Sect. 3) and the lack of further information, the exact grounding line position in 2008 remains vague.

5 In 2011 the glacier had substantially accelerated and in 2015 high velocities had further propagated inland by $\sim 1 \mathrm{~km}$ up to the edge of the subglacial trough at $\sim 9 \mathrm{~km}$ upstream. The limit of high velocities in 2015 coincides with a marked change of the TSX/TDX 2011-2014 elevation change rates, indicating that at this position the ice starts to float. Based on this evidence, we estimate that the grounding line position in 2011 was likely already located at the edge of the subglacial trough and had probably further retreated by $\sim 1 \mathrm{~km}$ in 2015 .

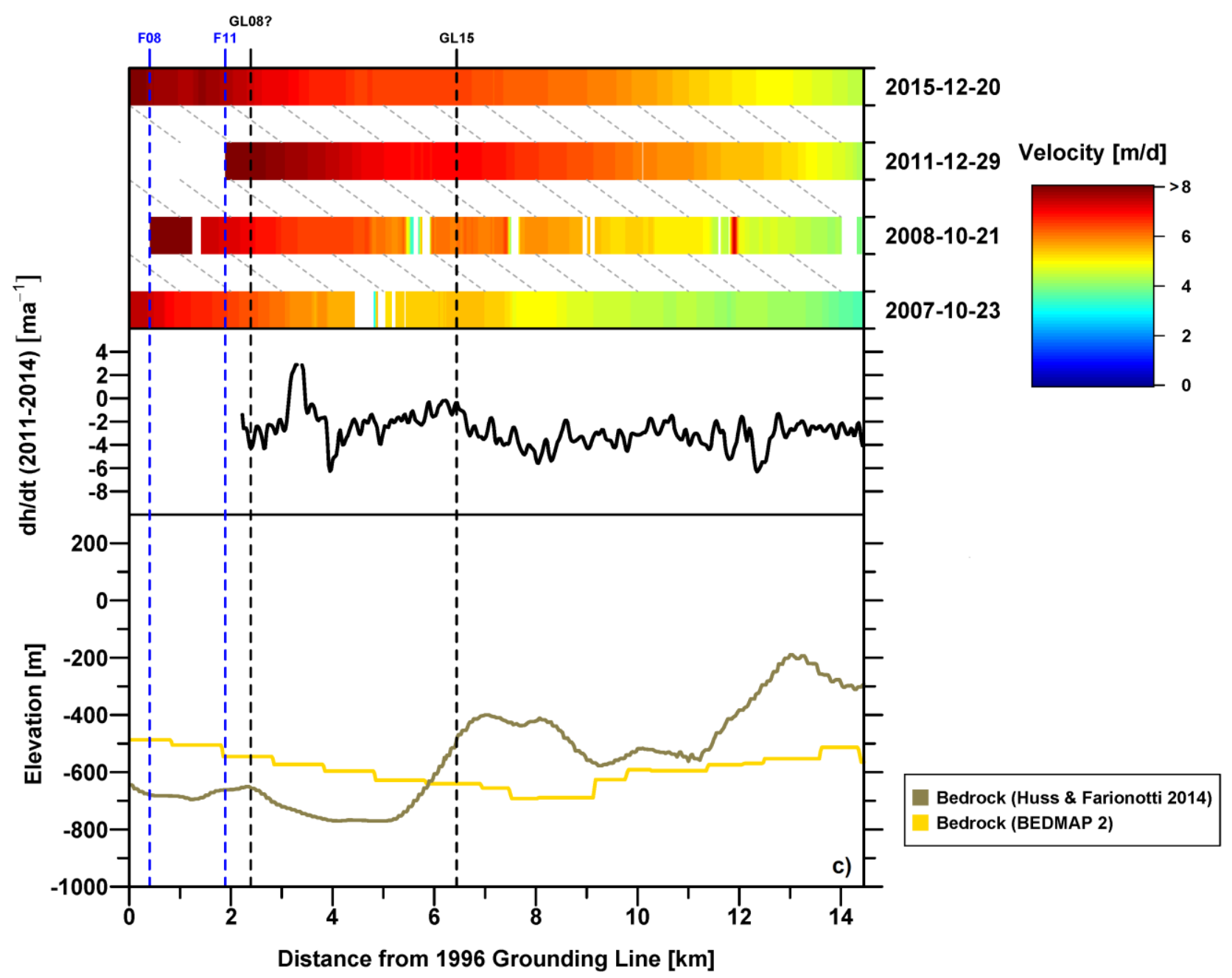


Figure S6 c reveals that velocities extracted along Profile 3 (Fig. 6) show an upstream propagation of high velocities between 2007 and 2008 of up to $11 \mathrm{~km}$. In 2008, the glacier front had retreated behind the 1996 grounding line. This indicates that in 2008 the grounding line must have been located upstream from its 1996 position. Since the acceleration had not yet propagated as far upstream as in 2011 and 2015, we assume that the 2008 grounding line was located more seawards than in

52011 and 2015 respectively. A possible grounding line location in 2008 is a smaller hill visible in the bedrock data close to the front in 2011 at $~ 2,5 \mathrm{~km}$ upstream. However, due to the limitations of the bedrock data (Sect. 3) and the lack of further evidence, the precise 2008 position remains unclear.

In 2011 and 2015 the glacier had markedly accelerated, indicating that the grounding line had further retreated. The 2011/2014 TSX/TDX dh/dt profile shows a slight drop in ice thinning rates at $\sim 6 \mathrm{~km}$ upstream of the 1996 grounding line

10 which coincides with the edge of the subglacial trough in the bedrock data. Although the change of elevation change rates is not as pronounced as on the other profiles, hydrostatic height anomalies along an OIB-flight path running close to this position (Fig. 6, Track 4) show that in 2014 the glacier was freely floating downstream. OIB data acquired in 2011 and 2014 (Fig. 6, Track 3 and 5) indicate that the ice is currently grounded upstream of the hill chain. We hence estimate the recent grounding line position to be located at the edge of the subglacial trough $\sim 6 \mathrm{~km}$ upstream. 


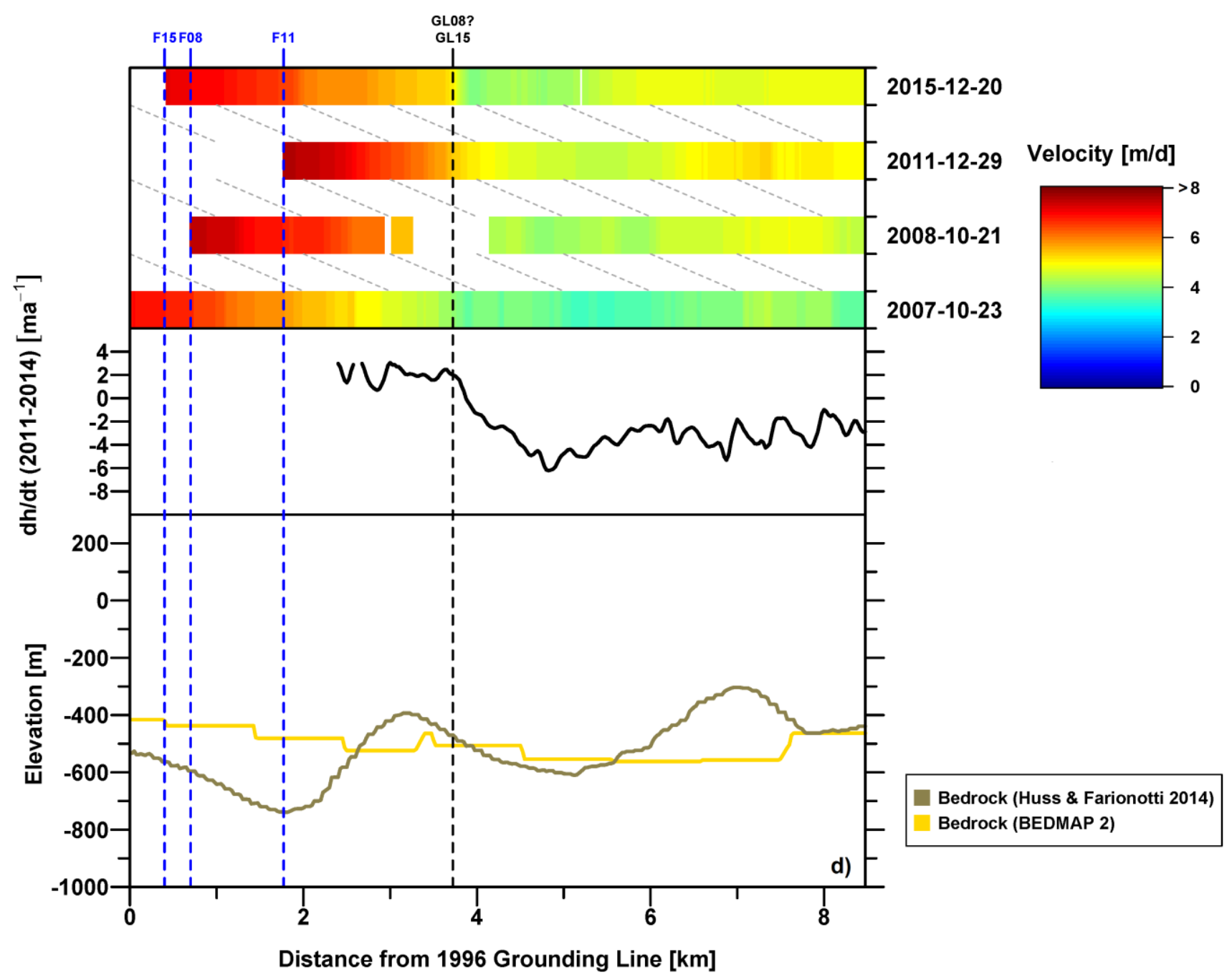

Figure S6 d shows that between 2007 and 2008 a pronounced acceleration is detected along Profile d (Fig. 6). In 2008 the glacier front had retreated behind the 1996 grounding line for the first time. Thus, the grounding line in 2008 must have been located upstream of the 1996 position in 2008. The velocity patterns look similar in 2008, 2011 and 2015, suggesting that no 5 further grounding line retreat occurred after 2008. We hence assume that the 2008 grounding line position is more or less identical with the recent location. However, given the lack of further evidence the precise grounding line position of 2008 remains vague.

A sharp increase in surface velocities is visible at 3-4 km upstream in 2011 and 2015. This location is consistent with a pronounced change in ice thinning rates visible on the TSX/TDX 2011-2014 dh/dt profile and on the map (Fig. S7), which 10 indicates that the ice is currently floating downstream. On the other hand, hydrostatic height anomalies along OIB tracks 4 
and 5 in Figure 6 reveal that the ice is grounded further upstream. Additionally the 2011 front was located $\sim 2 \mathrm{~km}$ upstream of the grounding line. Combining all of the information, we estimate the recent grounding line to be located at a position $\sim 3-$ $4 \mathrm{~km}$ upstream. However, the modeled bedrock data suggests that the grounding line is not situated on the upslope but on the downslope side of a subglacial hill. We hence cannot rule out that the hill may be shifted to the north in the modelled

5 bedrock data, or that - if the modelled bedrock topography is correct - the recent grounding line is located $\sim 1 \mathrm{~km}$ further to the south. 


\section{S7 Recent grounding line and TSX/TDX 2011-2014 elevation change}

Figure S7: Glacier surface elevation change on Fleming Glacier between 2011 and 2014 derived from TSX/TDX bistatic and monostatic acquisitions with final solution of the interpolated recent (2014) grounding line (pink line). Brown line: grounding line in 1996 from Rignot et al. (2005) and Rignot et al. (2011). Background: Mosaic of two Landsat-8 „Natural Color” images, acquired on 2015-09-16 5 CUSGS.

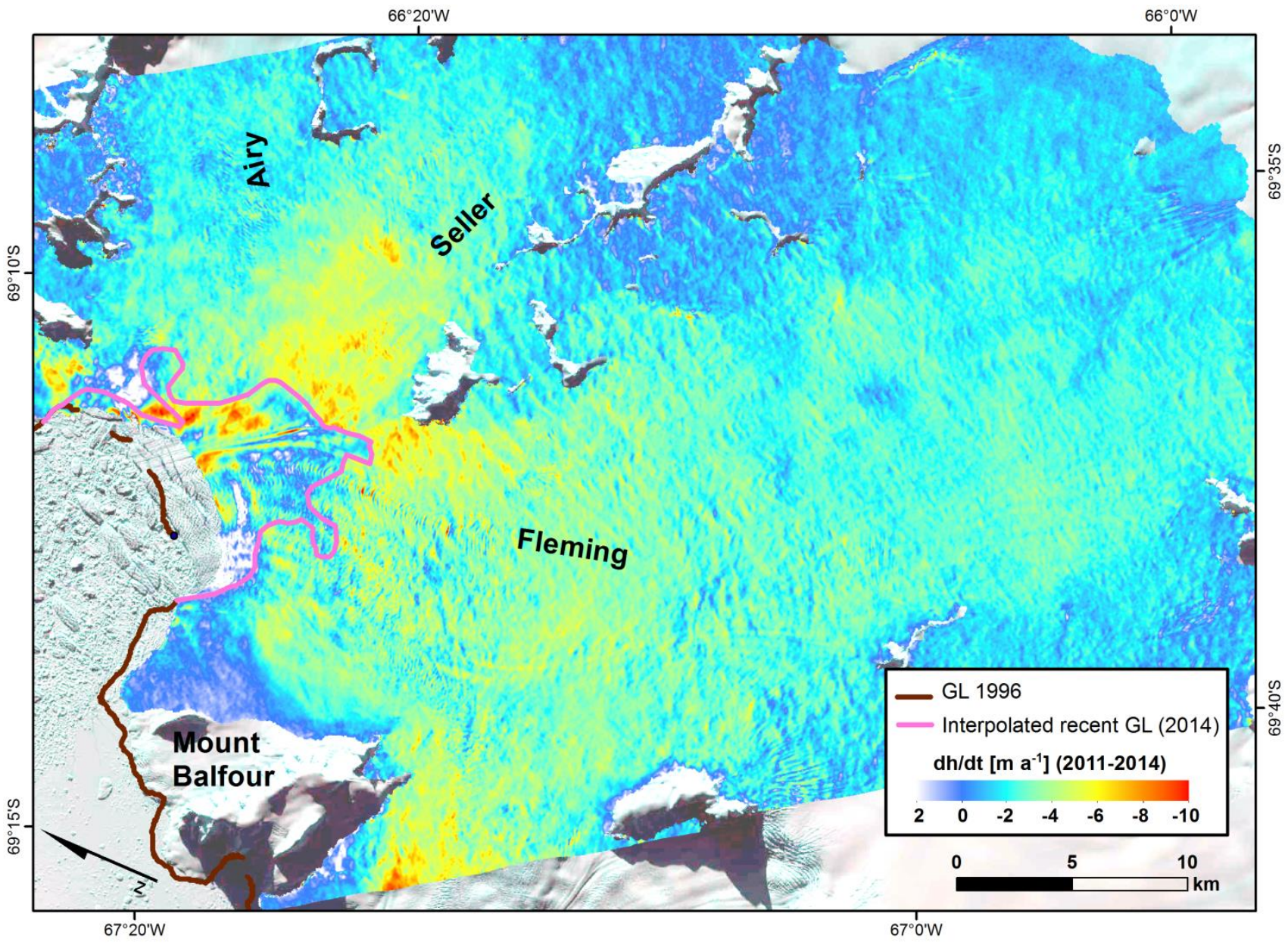




\section{References}

Bamber, J. and Bentley, C.: A comparison of satellite-altimetry and ice-thickness measurements of the Ross Ice Shelf, Antarctica, Annals of Glaciology, 20, 357-364, 1994.

Benn, D. I. and Evans, D. J. A.: Glaciers \& glaciation, Routledge, London, 2013.

5 Burgess, E. W., Forster, R. R., Larsen, C. F. and Braun, M.: Surge dynamics on Bering Glacier, Alaska, in 2008-2011, The Cryosphere, 6, 1251-1262, doi: 10.5194/tc-6-1251-2012, 2012.

Ferrigno, J. G.: Coastal-change and glaciological map of the Larsen Ice Shelf area, Antarctica, 1940-2005, Reston, Va., 2008.

Fretwell, P., Pritchard, H. D., Vaughan, D. G., Bamber, J. L., Barrand, N. E., Bell, R., Bianchi, C., Bingham, R. G., Blankenship, D. D., Casassa, G., Catania, G., Callens, D., Conway, H., Cook, A. J., Corr, H. F. J., Damaske, D., Damm, V., Ferraccioli, F., Forsberg, R., Fujita, S., Gim, Y., Gogineni, P., Griggs, J. A., Hindmarsh, R. C. A., Holmlund, P., Holt, J. W., Jacobel, R. W., Jenkins, A., Jokat, W., Jordan, T., King, E. C., Kohler, J., Krabill, W., Riger-Kusk, M., Langley, K. A., Leitchenkov, G., Leuschen, C., Luyendyk, B. P., Matsuoka, K., Mouginot, J., Nitsche, F. O., Nogi, Y., Nost, O. A., Popov, S. V., Rignot, E., Rippin, D. M., Rivera, A., Roberts, J., Ross, N., Siegert, M. J., Smith, A. M., Steinhage, D., Studinger, M., Sun, B., Tinto, B. K., Welch, B. C., Wilson, D., Young, D. A., Xiangbin, C. and Zirizzotti, A.: Bedmap2: improved ice bed, surface and thickness datasets for Antarctica, The Cryosphere, 7, 375-393, doi: 10.5194/tc-7-3752013, 2013.

Griggs, J. A. and Bamber, J. L.: Ice shelf thickness over Larsen C, Antarctica, derived from satellite altimetry, Geophys. Res. Lett., 36, doi: 10.1029/2009GL039527, 2009.

20 Griggs, J. A. and Bamber, J. L.: Antarctic ice-shelf thickness from satellite radar altimetry, Journal of Glaciology, 57, 485498, doi: 10.3189/002214311796905659, 2011.

Huss, M. and Farinotti, D.: A high-resolution bedrock map for the Antarctic Peninsula, The Cryosphere, 8, 1261-1273, doi: 10.5194/tc-8-1261-2014, 2014.

McNabb, R. W., Hock, R., O'Neel, S., Rasmussen, L. A., Ahn, Y., Braun, M., Conway, H., Herreid, S., Joughin, I., Pfeffer, W. T., Smith, B. E. and Truffer, M.: Using surface velocities to calculate ice thickness and bed topography. A case study at Columbia Glacier, Alaska, USA, Journal of Glaciology, 58, 1151-1164, doi: 10.3189/2012JoG11J249, 2012.

Rignot, E., Casassa, G., Gogineni, P., Kanagaratnam, P., Krabill, W., Pritchard, H. D., Rivera, A., Thomas, R., Turner, J. and Vaughan, D. G.: Recent ice loss from the Fleming and other glaciers, Wordie Bay, West Antarctic Peninsula, Geophys. Res. Lett., 32, doi: 10.1029/2004GL021947, 2005.

30 Rignot, E., Mouginot, J. and Scheuchl, B.: Antarctic grounding line mapping from differential satellite radar interferometry, Geophys. Res. Lett., 38, n/a, doi: 10.1029/2011GL047109, 2011.

Seehaus, T., Marinsek, S., Helm, V., Skvarca, P. and Braun, M.: Changes in ice dynamics, elevation and mass discharge of Dinsmoor-Bombardier-Edgeworth glacier system, Antarctic Peninsula, Earth and Planetary Science Letters, 427, 125135, doi: 10.1016/j.epsl.2015.06.047, 2015. 
van den Broeke, Michiel, van de Berg, Willem Jan and van Meijgaard, E.: Firn depth correction along the Antarctic grounding line, Antarctic Science, 20, 513-517, doi: 10.1017/S095410200800148X, 2008.

Wendt, J., Rivera, A., Wendt, A., Bown, F., Zamora, R., Casassa, G. and Bravo, C.: Recent ice-surface-elevation changes of Fleming Glacier in response to the removal of the Wordie Ice Shelf, Antarctic Peninsula, Annals of Glaciology, 51, $97-$ 102, doi: 10.3189/172756410791392727, 2010. 